\title{
Arquivo histórico e experimental para uma prática artístico-educativa
}

\author{
Amanda Midori da Costa Suzuki ${ }^{1}$ \\ DOI 10.20396/eha.vil4.3438
}

Introdução e estado da arte

O presente artigo configura-se na apresentação do projeto de investigação em desenvolvimento no âmbito do Programa Doutoral em Educação Artística da Universidade do Porto e Universidade de Lisboa, tendo sido concebido durante o primeiro ano curricular, no ano letivo de 2018/2019, com implementação iniciada no ano letivo de 2019/2020². Esta investigação tem por objeto de estudo a prática artístico-educativa de Elvira Leite (1936, Porto), artista plástica e professora que desde a década de 1960 vem atuando no cruzamento e deslocamento entre o artístico e o educativo, tornando-se uma das figuras mais pertinentes na constituição do campo de ação da educação artística em Portugal. No projeto será realizado um estudo exaustivo das suas práticas jogos, livros, projetos e estratégias artístico-educativas-, constituindo-se através delas um arquivo histórico e experimental, permeado pela perspectivação da sua prática num panorama nacional e internacional de experiências que atravessaram a educação artística e a prática artística na segunda metade do século XX, e que despoletaram, nos final dos anos 2000, a emergência do educational turn como campo de discussão nas artes contemporâneas. Este movimento, aqui formulado como lente epistemológica, será mobilizado e problematizado nas tensões e potências que abre para pensar a intersecção da arte com a educação.

Foi antes do 25 de abril de 1974 que Elvira Leite organizou nas caves do até então Liceu Rodrigues de Freitas, ateliers livres que misturavam expressão plástica com discussões políticas. Em 1976, no Largo Pena Ventosa, transformou a rua em local de oficina permanente na qual crianças, filhas dos moradores envolvidos no SAAL - Serviço Ambulatório de Apoio Local, estavam imersas num ambiente de exploração artística no espaço público. Licenciada em pintura na antiga Escola Superior de Belas-Artes do Porto, foi apenas no último ano do curso que passou a se interessar pela educação, ainda na década de 1960. A sua inquietude relacionada com a arte e o social, colocando

\footnotetext{
1 Instituto de Investigação em Arte, Design e Sociedade da Faculdade de Belas Artes da Universidade do Porto - i2ADS/FBAUP, Porto, Portugal Doutoranda em Educação Artística pela FBAUP.

2 São orientadoras deste projeto de doutoramento as professoras doutoras Catarina Silva Martins (FBAUP, PT) e Rita Bredariolli (IA-UNESP, BR).
} 
questões a si própria tais como "será que a arte pode ser para todos?"3 a fez afastar-se de um campo restrito da arte, com as suas bienais, galerias e prêmios - apesar de ter obtido em seu início de carreira reconhecimento nesta esfera consagrada - vindo a estabelecer a sua prática maioritariamente no campo da educação, a partir da sua atuação como professora no ensino público, mantendo junto com esta função aquilo que denomina como "escola paralela": os projetos de educação pela arte implementados em ateliers, museus e em comunidades de vulnerabilidade social ${ }^{4}$.

Num período que envolveu o pré e o pós Revolução de 1974, que marcou o fim do período ditatorial em Portugal e a retomada da democracia, Elvira encontrou no exterior o aporte teórico e prático que não havia em Portugal, estando em contato com intelectuais ligados ao movimento da livre expressão: Arno Stern, Viktor Lowenfeld e Herbert Head. Foi em 1974 que criou os seus primeiros jogos visuais, concebidos com Manuela Malpique e em diálogo com Bruno Munari ${ }^{5}$, tendo dois deles sido reeditados em 2019 pela Architoys ${ }^{6}$.

Desenvolvendo metodologias e abordagens educativas muito próprias, voltadas sobretudo para o trabalho em grupo, partindo de problemas e sob a lógica de projeto, Elvira Leite elaborou literatura sobre pedagogia ${ }^{7}$, criatividade ${ }^{8}$ e trabalho de projeto 9 . A partir dos anos 1990 começou a exercer consultoria educativa em instituições culturais como Museu de Serralves, Museu Nacional Soares dos Reis e Centro Regional de Artes Tradicionais, fazendo derivar daí centenas de propostas de oficinas, principalmente para turmas escolares e famílias, documentadas em diversas publicações da Fundação Serralves.

Apesar das profusas produções de Elvira Leite, ainda são raras as investigações que sistematizem e analisem o seu trabalho. As entrevistas até ao momento publicadas são importantes contributos para uma aproximação ao pensamento e à atuação de Elvira Leite, nas quais encontramos a memória e a narração em primeira pessoa acerca dos acontecimentos. Já a tese doutoral de Maria

\footnotetext{
3 Entrevista concedida à Catarina Martins, Ana Catarina Almeida, Joana Mendonça, Lígia Lima e Michelle Domingos em 2012. Acervo pessoal de Catarina Martins. Parte desta entrevista está disponível em: MARTINS, C. Elvira Leite em conversa com Ana Catarina Almeida, Joana Mendonça, Lígia Lima e Michelle Domingos. In: MARTINS, C.; TERRASÊCA, M.; MARTINS, V. (Org). À procura de renovações de estratégias e de narrativas sobre educação artística: Escritas posteriores ao Encontro Internacional de Cabo Verde. Porto: CESTO Cooperativa Cultural, CRL, 2012. p. $229-233$. 4 Sobre a "escola paralela" Elvira Leite afirma: "eu tenho que ter mais do que um trabalho. Mesmo quando estava na escola, o facto de falar na escola paralela, fosse ela qual fosse, tinha que ter outro tipo de actividade. Só com a Escola, eu até seria má professora"; e ainda "organizei em parceria oficinas fora da escola, que eu digo que fazem parte de uma Escola Paralela; sempre tive esse refúgio, essa complementaridade, esse recurso que eu considerei e considero de grande relevância para se ser um bom profissional no campo da educação artística". Apud MARTINS, M. (2014). Currículo, subjetividade e trajetória profissional na educação das artes visuais: Intérpretes da educação artística em Portugal. 2014. 552 f. Tese (Doutoramento em Arte e Educação) - Faculdade de Belas Artes, Universidade de Barcelona, Espanha. passim.

5 Dezenas de jogos e livros-jogos foram publicados pelas Edições ASA, em 1974, editora sediada no Porto, Portugal.

6 O "Jogo das Concordâncias" e "Jogo dos Constrastes" podem ser visualizados em: https://architoys.pt/

7 Leite, E., Malpique, M., \& Carneiro, A. (1983). O espaço pedagógico: A casa, o caminho casa-escola, a escola. Porto: Afrontamento.

8 Leite, E., \& Malpique, M. (1986). Espaços de criatividade: a criança que fomos/a criança que somos... através da expressão plástica. Porto: Afrontamento.

9 Leite, E., Malpique, M., \& Santos, M. (1989). Trabalho de Projecto. Porto: Afrontamento.
} 
da Graça Martins ${ }^{10}$ presenteia-nos com uma extensa entrevista. Porém, em nenhum deste casos seus desenvolvimentos artísticos e educativos são tomados como objeto de estudo.

Diferentemente aconteceu com figuras internacionais como Joseph Beuys ou Allan Kaprow que, nas décadas de 1960 e 1970, estavam a ensaiar práticas situadas na divisa entre a arte, a educação e a vida. Estes artistas são hoje considerados referências para o denominado social turn da arte, termo conceitual que demarca uma zona de problematização que emerge com a mudança verificada, sobretudo nas práticas artísticas a partir dos anos 1990, em que o componente social e participativo dos projetos artísticos passa a ganhar relevância em face do caráter estético ou objetual dos trabalhos. O social turn começa a adquirir teorização e constituir um corpo epistemológico específico a partir do pensamento de autores como Nicolas Bourriaud ${ }^{11}$ - com sua proposição de estética relacional, já muito criticada pela superficialidade com que se remete ao envolvimento social -e Claire Bishop ${ }^{12}$, com a crítica que faz acerca da componente ética sobrepor-se e limitar a capacidade antagonista da arte.

É no interior deste território problematizador iniciado com o social turn que vemos eclodir, já no final dos anos 2000, o olhar atento para outra viragem no campo das artes, o educational turn, transformando-se em um novo campo epistemológico das artes contemporâneas. O educational turn sinaliza o redirecionamento das práticas artísticas e curatoriais à educação, em que determinadas práticas, até antes imperceptíveis para o campo da arte, passam a ser observadas, lidas, problematizadas, ao mesmo tempo que legitimadas. Muitos/as autores/as consideram que o direcionamento da arte à educação se dá com a adoção de recursos educativos tais como aulas, conversas, conferências, oficinas, bibliotecas, escolas de arte, universidades, etc., transformando a educação em um novo media para as artes ${ }^{13}$. As abordagens seminais que se dirigem à esta viragem são encontradas em Kristina Lee Podesva ${ }^{14}$, Irit Rogoffi5 e Paul O'Neil e Mike Wilson ${ }^{16}$, num âmbito anglo-saxão europeu, e na língua portuguesa começa-se a difundir a experiência e o pensamento latino-americano com Pablo Helguera e Mônica Hoff17, Mônica Colçalves ${ }^{18}$ e Luiz Camntizer, Palblo Helguera e Betty

\footnotetext{
10 MARTINS, M., op. cit.

11 BOURRIAUD, N. Estética Relacional. Tradução: Cecília Beceyro e Sergio Delgado. $2^{\text {a }}$ ed. Buenos Aires: Adriana Hidalgo Editora, 2008.

12 BISHOP, C. The Social Turn: Collaboration and Its Discontents. Artforum, n. Fevereiro, p. 178-183, 2006.

13 Como propõe Kristina Lee Podesva em PODESVA, K. (2007) A Pedagogical Turn: brief notes on Education as Art. Fillip 6, summer, 2007. Disponível em:<http://fillip.ca/content/a-pedagogical-turn>. Acesso em: 10 jan 2019.

14 Ibidem.

15 ROGOFF, I. (2008). Turning. e-flux Journal, n. o, november, 2008. Disponível em: <em http://www.e-flux.com/journal/oo/68470/turning/> Acesso em: 25 abr 2018 .

16 O'NEIL, P.; WILSON, M. (Ed.). Curating and the educational turn. London: Open Editions, De Appel, 2010.

17 HELCUERA, P.; HOFF, M. (Org.). (2011). Pedagogia no campo expandido. Porto Alegre: Fundação Bienal de Artes Visuais do Mercosul.

18 GONÇALVES, M. A virada educacional nas práticas artísticas e curatoriais contemporâneas e o contexto de arte brasileiro. 2014 . 272 f. Dissertação
} 
Marín ${ }^{19}$.

O educational turn é um campo de estudo não-pacificado, configurado com perspectivas diversificadas e antagônicas que fazem emergir fricções entre o cruzamento da arte e da educação, erigindo problemáticas relativas: às noções de participação, em que se questiona a suas características, contextos e finalidades; às concepções de educação postas em funcionamento sob a égide da estética pedagógica; aos contextos socioculturais e políticos nos quais tais práticas estão implicadas; às motivações de artistas e coletivos e que, na generalidade dos estudos, ligam-se à Pedagogia do Oprimido, de Paulo Freire ${ }^{20}$, e ao Mestre Ignorante, de Jacques Rancière ${ }^{21}$, sobretudo num enquadramento europeu; e ao sentido mesmo de arte e cultura presente em tais projetos.

O educational turn é o fator que será nesta investigação utilizado como lente epistemológica, dando-nos a condição de estrutura de raciocínio e percepção que hoje nos permite olhar para as práticas de Elvira Leite, trazendo-as à tona da nossa contemporaneidade mas também problematizando, interrogando e inferindo acerca das possibilidades e impossibilidades, das contradições, dos constrangimentos e das potencialidades que são derivadas deste cruzamento entre o artístico e o educativo. Neste sentido, importa compreender e situar a atuação de Elvira Leite em relação com o panorama português e com um panorama internacional de experiências que permearam a educação artística na segunda metade do século XX.

É possível compreender que foi esta condição epistemológica do educational turn que possibilitou que fossem realizadas recentemente duas exposições a partir dos registros fotográficos de Elvira Leite, produzidos durante as oficinas implementadas no âmbito do já citado SAAL. Quem te ensinou? - ninguém, 2016, FBAUP, Porto 22, e Pedagogy of the Streets: Porto 1977, 2019, Mishkin Gallery, Nova lorque ${ }^{23}$, inserem a prática artístico-educativa de Elvira Leite em um circuito de visibilidade artística. Estas exposições, ao mesmo tempo em que demonstram a pertinência de uma investigação baseada em suas práticas, localizando-as em discussões correntes, também evidenciam que só agora, já quase no final da segunda década do século XXI e mediante a valorização internacional das práticas artístico-educativas, começa-se a construir um pensamento capaz de estudar e observar as realizações de Elvira Leite numa perspectiva nunca antes ensaiada.

Ainda neste enquadramento, vale ressaltar que em Portugal foram lançadas apenas recente-

\footnotetext{
(Mestrado em Artes Visuais) - Instituto de Artes, Universidade Federal do Rio Grande do Sul, Rio Grande do Sul, 2014.

19 CAMNTIZER, L.; HELGUERA, P.; MARÍN, B. Art and Education. Oregon: Publication Studio, 2014.

20 FREIRE, P. Pedagogia do oprimido. 63 ${ }^{\mathrm{a}}$ ed. Rio de Janeiro, São Paulo: Paz e Terra, 2017.

21 RANCIÈRE, ]. O mestre ignorante: Cinco lições sobre a emancipação intelectual. Belo Horizonte: Autêntica, 2002.

22 LEITE, E. Quem te ensinou? - ninguém. Porto: Pierrot le fout, 2016.

23 MARQUES, S. (Ed.). Pedagogy of the streets: Porto 1977. Porto: Pierrot le fout, 2019.
} 
mente as primeiras publicações que dedicam parte do seu estudo ao educational turn ${ }^{24}$. Porém, tais investigações apresentam mormente uma revisão de literatura que mantém as racionalidades das fontes estudadas sem reconfigurar o educational turn como problemática.

\section{Objetivos}

O projeto configura-se em torno de dois eixos investigativos, cuja articulação contínua possibilitará enfrentar a discussão acerca das problemáticas artístico-educativas contemporâneas.

\section{Práticas artístico-educativas de Elvira Leite}

Tendo como foco o levantamento e o estudo exaustivo de suas produções, este eixo promoverá a constituição de um arquivo histórico e experimental composto por práticas artístico-educativas, tais como jogos, projetos e estratégias, elaborados por Elvira desde a década de 1960, objetivandose:

- Repertoriar e compreender a sua produção, posicionando-a no território limítrofe entre a arte e a educação;

- Tornar visíveis processos e produtos artístico-educativos, de modo a que possam ser reativados ou reelaborados por artistas-educadores na contemporaneidade.

\section{Contextos artístico-educativos de Elvira Leite}

Esta vertente se centrará na compreensão da atividade de Elvira Leite inserida nos panoramas nacional e internacional da arte e educação, desde a segunda metade do século XX, visando:

- Compreender as consonâncias e dissonâncias de sua prática em diálogo com a educação artística e a prática artística em Portugal a partir dos anos 1960;

- Analisar e depreender a rede de referências e contaminações que contribuem na formação do caráter artístico-educativo das realizações de Elvira;

- Situar as suas produções em face da viragem das artes para a educação numa amplitude internacional.

24 São exemplos: MARTINS, J. Eurico Gonçalves e a expressão livre da criança. 2018. 188f. Dissertação (Mestrado em História da Arte Contemporânea) - Faculdade de Ciências Sociais e Humanas, Universidade Nova de Lisboa, Portugal; e OLIVEIRA, M. A educação nos discursos da arte contemporânea: participação, colaboração, confrontação e criação. 2018. 110f. Dissertação (Mestrado em Educação Artística) - Faculdade de Belas Artes, Universidade de Lisboa, Portugal. 
Plano metodológico

O plano metodológico da investigação se organiza ao redor dos eixos investigativos mencionados, dividindo-se em cinco áreas de atuação, sendo elas:

\section{Estudos teórico-metodológicos}

Desenvolvimento de estudos visando estabelecer pontos de ancoragem teórica e epistemológica sobre história, memória, arquivo e experiência a serem considerados: na análise do acervo pessoal de Elvira Leite; nas entrevistas semi-estruturadas e abertas com Elvira Leite; e no olhar a ser assumido ante os fatos e enunciados históricos derivados do arquivo pessoal, colaborando, consequentemente, na construção de um posicionamento ante a constituição do arquivo histórico e experimental.

\section{Práticas artístico-educativas de Elvira Leite}

Baseado num primeiro levantamento de todas as produções de Elvira Leite através da Biblioteca Nacional Portuguesa e da Biblioteca de Serralves, haverá a implementação de um trabalho em proximidade com Elvira Leite e com as suas práticas, procedendo-se à análise de entrevistas já publicadas, à leitura de textos de sua autoria e à recolha de informações sobre seus projetos, proposições, jogos e estratégias artístico-pedagógicas implementados. As entrevistas serão feitas regularmente durante uma fase de repertoriação geral de sua produção, seguida do levantamento documental das práticas específicas que forem selecionadas para o aprofundamento de estudo.

O arquivo a ser formado nesta investigação será possivelmente virtual (website), com caráter público e acessível. Parte das tarefas que concernem o desenvolvimento do arquivo assente nas práticas de Elvira Leite serão realizadas em articulação com uma equipe de investigadores e terá a colaboração técnica do i2ADS, centro de investigação no qual a pesquisa se insere, sobretudo na estruturação do website, no seu alojamento e nas componentes de digitalização e fotografia de documentos e objetos.

\section{Contextos artístico-educativos de Elvira Leite}

Será feita uma revisão literária exaustiva e sistemática visando possibilitar uma compreensão ampla do âmbito epistemológico construído sobre o educational turn, com seleção e análise 
de textos de autores considerados de referência para a leitura da prática de Elvira Leite. As tarefas acontecerão concomitantemente com a recolha e sistematização de dados acima mencionada, de modo a ativar o educational turn como lente epistemológica problematizadora.

Ainda neste âmbito, será feita pesquisa acerca das referências e contaminações pedagógicas e artísticas presentes na prática de Elvira Leite, dentre as quais estão Victor Lowenfeld, Arno Stern e Bruno Munari, selecionados com base nas entrevistas já publicadas, prevendo-se que durante as entrevistas emerjam outras referências.

Também será conduzida investigação literária que possibilite uma compreensão das consonâncias e dissonâncias de Elvira Leite com o seu tempo histórico, fundamentada na pesquisa e leitura sistemática sobre a educação artística e a prática artística em Portugal a partir dos anos 1960, e o contexto educativo português pós-revolução de 1974. Será, também considerado o cenário internacional da viragem da arte para a educação, no mesmo período, para que haja enfrentamento entre diferentes contextos de arte e educação.

\section{Discussão e divulgação de resultados}

Por fim, o projeto prevê a realização de uma exposição final que contemplará a apresentação do arquivo (website) e registros documentais e textuais coletados e produzidos durante a investigação, objetivando promover debate na esfera artística e educativa.

\section{Considerações finais}

Por se assentar num projeto de investigação ainda numa fase inicial de desenvolvimento, o texto aqui exposto evidencia a generalidade de uma pesquisa que faz as suas primeiras movimentações para se inscrever naquela que é uma compreensão histórica da emergência do cruzamento entre o artístico e o educativo, fundamentada nas produções realizadas por Elvira Leite no âmbito português. Terá como fim último contribuir para a criação de novas narrativas para a intersecção arte-educação, auxiliando potencialmente a encontrar as repetições e naturalizações sobreviventes no interior dos contextos da produção artística-educativa contemporânea. 


\section{Referências bibliográficas}

BISHOP, C. The Social Turn: Collaboration and Its Discontents. Artforum, n. Fevereiro, p. 178-183, 2006.

BOURRIAUD, N. Estética Relacional. Tradução: Cecília Beceyro e Sergio Delgado. $2^{\mathrm{a}}$ ed. Buenos Aires: Adriana Hidalgo Editora, 2008.

CAMNTIZER, L.; HELGUERA, P.; MARÍN, B. Art and Education. Oregon: Publication Studio, 2014.

FREIRE, P. Pedagogia do oprimido. 63ª ed. Rio de Janeiro, São Paulo: Paz e Terra, 2017.

GONÇALVES, M. A virada educacional nas práticas artísticas e curatoriais contemporâneas e o contex to de arte brasileiro. 2014. 272 f. Dissertação (Mestrado em Artes Visuais) - Instituto de Artes, Universidade Federal do Rio Grande do Sul, Rio Grande do Sul, 2014.

HELGUERA, P.; HOFF, M. (Org.). Pedagogia no campo expandido. Porto Alegre: Fundação Bienal de Artes Visuais do Mercosul, 2011.

LEITE, E.; MALPIQUE, M. Espaços de criatividade: a criança que fomos/a criança que somos... através da expressão plástica. Porto: Afrontamento, 1986.

LEITE, E.; MALPIQUE, M.; CARNEIRO, A. O espaço pedagógico: A casa, o caminho casa-escola, a escola. Porto: Afrontamento, 1983.

LEITE, E.; MALPIQUE, M.; SANTOS, M. Trabalho de Projecto. Porto: Afrontamento, 1989.

LEITE, E. Quem te ensinou? — ninguém. Porto: Pierrot le fout, 2016.

MARQUES, S. (Ed.). Pedagogy of the streets: Porto 1977. Porto: Pierrot le fout, 2019.

MARTINS, C. Elvira Leite em conversa com Ana Catarina Almeida, Joana Mendonça, Lígia Lima e Michelle Domingos. In: MARTINS, C.; TERRASÊCA, M.; MARTINS, V. (Org). À procura de renovações de estratégias e de narrativas sobre educação artística: Escritas posteriores ao Encontro Internacional de Cabo Verde. Porto: GESTO Cooperativa Cultural, CRL, 2012. p. 229-233.

MARTINS, ]. Eurico Conçalves e a expressão livre da criança. 2018. 188f. Dissertação (Mestrado em História da Arte Contemporânea) - Faculdade de Ciências Sociais e Humanas, Universidade Nova de Lisboa, Portugal.

MARTINS, M. Currículo, subjetividade e trajetória profissional na educação das artes visuais: Intérpretes da educação artística em Portugal. 2014. 552 f. Tese (Doutoramento em Arte e Educação) - Faculdade de Belas Artes, Universidade de Barcelona, Espanha.

OLIVEIRA, M. A educação nos discursos da arte contemporânea: participação, colaboração, confrontação e criação. 2018. 110f. Dissertação (Mestrado em Educação Artística) - Faculdade de Belas Artes, Universidade de Lisboa, Portugal.

O'NEIL, P.; WILSON, M. (Ed.). Curating and the educational turn. London: Open Editions, De Appel, 2010.

PODESVA, K. A Pedagogical Turn: brief notes on Education as Art. Fillip 6, summer, 2007. Disponível em: <http://fillip. ca/content/a-pedagogical-turn>. Acesso em: 10 jan. 2019.

RANCIÈRE, ]. O mestre ignorante: Cinco lições sobre a emancipação intelectual. Belo Horizonte: Autêntica, 2002.

ROCOFF, I. Turning.e-flux]ournal, n. o, november, 2008. Disponível em:<em http://www.e-flux.com/journal/oo/68470/ turning/>. Acesso em: 25 abr. 2018. 